\title{
Estimation of Salivary Flow Rate in Uncontrolled Diabetic Patients and Prediabetic Patients - A Hospital Based Study
}

\author{
Pavithra.A.S1, M. P. Brundha ${ }^{1 *}$ and Preejitha V.B ${ }^{2}$ \\ ${ }^{1}$ Saveetha Dental College and Hospitals, Saveetha Institute of Medical and \\ Technical Sciences,Saveetha University, Chennai, Tamilnadu, India, 600077 \\ ${ }^{1}$ Associate Professor, Department of Pathology, Saveetha Dental College and Hospitals, Saveetha \\ Institute of Medical and Technical Science, Saveetha university, Chennai, Tamilnadu, India, 600077 \\ ${ }^{2}$ Tutor, Department of Pathology, Saveetha Dental College and Hospitals, Saveetha Institute of \\ Medical and Technical Sciences, Saveetha University, Chennai, Tamilnadu, India, 600077
}

\section{ABSTRACT}

Diabetes Mellitus is a disease that occurs when the blood glucose is too high. Saliva is a most valuable oral fluid. It is essential for alimentation, remineralization. of teeth, and the pharyngeal disorders and requires early diagnosis protection and lubrication of oral mucosal tissues. An unstimulated whole saliva flow rate in a normal person is $0.3-0.5 \mathrm{ml}$ per minute, and below $0.1 \mathrm{ml}$ per minute is significantly abnormal. The aim of the study is to estimate the salivary flow rate between prediabetic and uncontrolled diabetic patients. The subjects are asked not to eat or drink 30 minutes prior to beginning the collection of the saliva sample after swallowing all saliva they are asked to accumulate new saliva and discharge into the tube for every 60 seconds for a period of 5 minutes. The saliva sample was collected from 25 Pre diabetic patients ranging from (80 to 130mg/dl) and 25 uncontrolled diabetic patients ranging more than $250 \mathrm{mg} / \mathrm{dl}$. The samples were selected from saveetha dental college. The collected in the graduated disposable syringe of $3 \mathrm{ml}$ and the reading was noted and analysed statistically. The salivary flow rate for uncontrolled diabetic patients is less than pre-diabetic patients. Salivary flow is required for normal metabolism. It gives protection to the oral cavity.

\section{KEY WORDS: SALIVARY FLOW, PREDIABETIC, UNCONTROLLED DIABETIC, SALIVARY RATE.}

\section{INTRODUCTION}

Diabetes Mellitus is a disease that happens when the blood sugar is just too high. Blood sugar is the main source of energy and comes from the food you eat.

\section{ARTICLE INFORMATION}

*Corresponding Author: brundha.sdc@saveetha.com Received 20th June 2020 Accepted after revision 3rd August 2020 Print ISSN: 0974-6455 Online ISSN: 2321-4007 CODEN: BBRCBA

Thomson Reuters ISI Web of Science Clarivate Analytics USA and Crossref Indexed Journal

\section{Clarivate}

crosser

NAAS Journal Score 2020 (4.31) SJIF: 2020 (7.728)

A Society of Science and Nature Publication,

Bhopal India 2020. All rights reserved.

Online Contents Available at: http//www.bbrc.in/

Doi: $h t t p: / / d x$.doi.org/10.21786/bbrc/13.7/46
Insulin, a hormone made by the pancreas, helps glucose from food get into the cells to be used for energy (Asfandiyarova, 2015). It is a widespread metabolic disease-causing well-documented deleterious effects on the overall health of a private(Bikbov and Surkova, 2016). Multiple epidemiologic studies have suggested that diabetes may be a risk factor for the event of oral diseases in humans. Diabetes is perhaps the foremost frequent metabolic disease with the salivary implication(Keen, 2008). Type 2 diabetes currently affects 250 million people worldwide, and about 300 million people with 
borderline diabetes are at increased risk of type 2 diabetes(Molitvoslovova and Galstyan, 2013). Diabetes mellitus may be a complex multisystem disorder characterized by relative or absolute insufficiency of insulin secretion and/or concomitant resistance to the metabolic action of insulin on track tissues (Galloway, Potvin and Shuman, 1988).

The abundant oral manifestations seen in DM make it likely for dentists to return in touch with a big number of diabetic patients(LeRoith, Taylor and Olefsky, 2004). It's estimated that around the turn of the century, there have been 40 million diabetics in India. Oral fluid or whole saliva may be a complex chemical of teeth and oral soft tissues, consisting mainly of water, essential electrolytes, glycoproteins, antimicrobial enzymes, and various other important constituents like glucose and amylase(Lee, Jung and Choi, 2020).

DM has been consistently documented to be related to altered salivary composition and performance. This disrupts the homeostasis of the mouth, making it vulnerable to various oral alignments(Jongerius, van Limbeek and Rotteveel, 2004). Oral physicians hold the responsibility of recognizing significant associations between certain oral anomalies(Syrjälä et al., 2011). Saliva may be the most precious oral fluid that is always taken without any consideration. it's critical to the preservation and maintenance of oral health, yet it receives little attention until quantity or quality is diminished(Hegde, 2016). Consequently, it's necessary for clinicians to possess an honest knowledge domain concerning the tradition of salivary flow and performance. Medical complications related to diabetes include renal disease, retinopathy, neuropathy, peripheral vascular disease, and a coronary heart condition(Norasettkul, Gonlachanvit and Patcharatrakul, 2017). Several factors may account for the poor correlation between blood and saliva glucose concentrations prevailing in diabetic subjects.

They include oral retention of alimentary carbohydrates, glucose utilization by oral bacteria, the release of carbohydrates from salivary glycoproteins, and contamination of saliva by an outsized outflow of crevicular fluid in patients with a poor gingival status(Dawes and Watanabe, 1987). Type 1 diabetes results from the pancreas' failure to supply enough insulin thanks to the loss of beta cells. This type was previously mentioned as "insulin-dependent diabetes mellitus" (IDDM) or "juvenile diabetes". The loss of beta cells is caused by an autoimmune response(Shalal, no date). The explanation for this autoimmune response is unknown.Type 2 diabetes begins with insulin resistance, a condition during which cells fail to reply to insulin properly. because the disease progresses, a scarcity of insulin can also develop. This form was previously mentioned as "non-insulin-dependent diabetes mellitus" (NIDDM).

The foremost common cause may be a combination of excessive weight and insufficient exercise(Habibe et al., 2020).Hyperglycemia and a few disturbances in the antioxidant system cause free radicals production and oxidative stress. They reduce hyperglycemia by increasing urinary glucose excretion and exert favorable effects beyond glucose control with consistent weight, vital signs, and serum acid reductions(Garrett, Ekström and Anderson, 1998). DM may be a complex multisystem disorder characterized by relative or absolute insufficiency of insulin secretion and/or concomitant resistance to the metabolic action of insulin on track tissues(Babiker et al., 2020). The abundant oral manifestations seen in DM make it likely for dentists to return in touch with a big number of diabetic patients. It's estimated that around the turn of the century, there have been 40 million diabetics in India, and worldwide, the prevalence of diabetes is assumed to have doubled between 1994 and 2017, with about 240 million people now affected by the disease(Zerbe, Vinicor and Robertson, 1979).

Saliva is important for alimentation, remineralization of teeth, and the pharyngeal disorders and requires early diagnosis protection and lubrication of oral mucosal tissues, and intervention(Metz, Nice and LaPlaca, 1967). Large variability in salivary flow diminished output can have deleterious effects on oral and systemic health rates within and between individuals has been reported. Saliva consists of organic, inorganic, and macromolecules. Calcium and phosphate ions are both involved in calculus formation and in protecting against caries(Zarif and Norris, 2014). Salivary proteins have protective antimicrobial, lubricative and digestive functions, which give a barrier between toxins and oral soft tissues and modulate salivary calcium and phosphate chemistry. Amylase is related to digestive function and, to a particular extent, it's going to play a task in modulating the adhesion of bacterial species to the teeth(Erismis, 2016).

\section{MATERIAL AND METHODS}

Sample collection: The saliva sample was collected from 25 Pre diabetic patients whose blood glucose levels range from ( 80 to $130 \mathrm{mg} / \mathrm{dl}$ ) and 25 uncontrolled diabetic patients whose blood glucose levels range more than $250 \mathrm{mg} / \mathrm{dl}$. The subjects were selected from Saveetha Dental College and Hospital in the month of November 2019.The subjects are asked to wait for 30 minutes after eating, drinking, smoking before beginning the collection of the saliva sample. The participants were requested to rest for 5 minutes with eyes open without stimulating saliva. Before collection, they are asked to rinse their mouth with water. After swallowing all saliva they are asked to accumulate new saliva and discharge into the tube every 60 seconds for a period of 5 minutes (figure 1).

Inclusion Criteria: Selection criteria include the diabetic patients who visited Saveetha dental college and were willing to participate in the study. Patients' blood glucose level range from $(80-130 \mathrm{mg} / \mathrm{dl})$ and more than $250 \mathrm{mg} / \mathrm{dl}$ level were included in the study. The age limit included in this study was 20-60 years. 
Exclusion Criteria: Diabetic patients who were not willing to participate were excluded from this study. Patients with normal blood glucose level and the blood glucose level from 130-240mg/dl were not included in this study. Age less than 20 years and more than 60 years were not included in this study.

Sampling method: Sampling method used in this study to select the study population is the Random sampling method.

Data Collection and Tabulation: The collected saliva is measured by collecting it in a graduated disposable syringe of $3 \mathrm{ml}$ and the reading was noted. The amount of saliva in ml divided by time in duration was recorded as mean salivary flow rate. This method is more specific than the traditional method. The salivary flow rate of the patient was entered into the excel sheets and then tabulation of the data was done finally and the question comparison was done. The representation of the data is through the bar graph.

Statistical Analysis: The statistical software used IBM SPSS V22.The statistical tests used were descriptive analysis and unpaired T -test. Significant $\mathrm{p}$ value was set at $<0.05$.

Figure 1: Represents the sample of saliva collection from the patient.

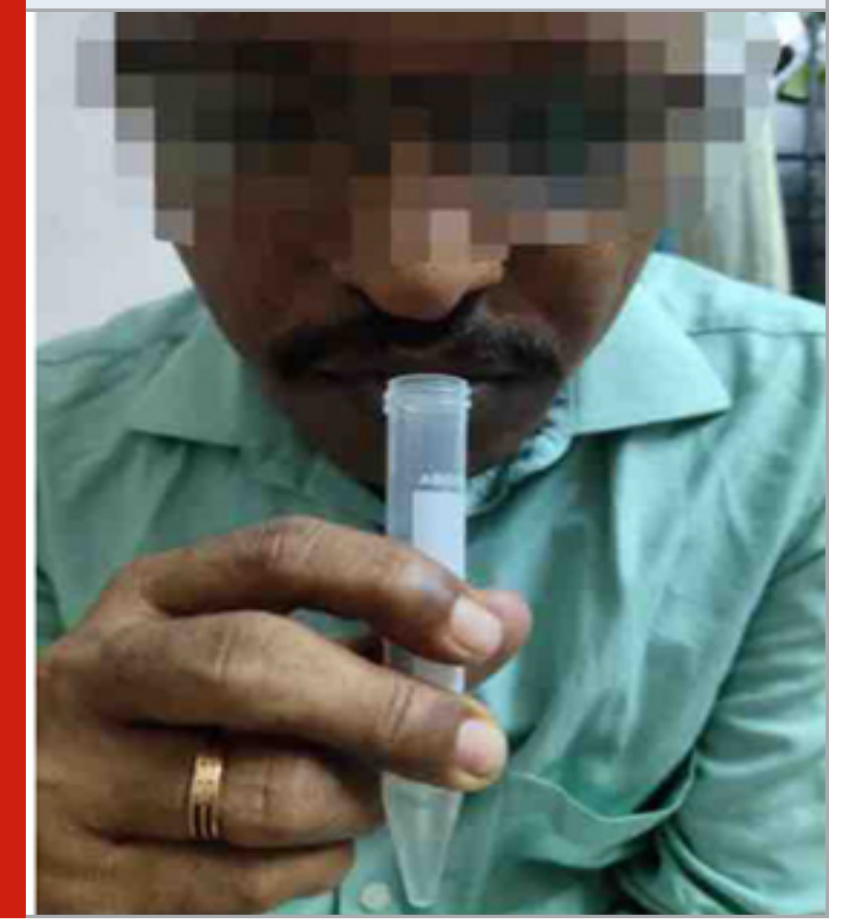

\section{RESULT AND DISCUSSION}

From table 1, it is seen that Prediabetic patients have a minimum range of salivary flow which is $1.2 \mathrm{ml}$ and the maximum range of salivary flow is $2 \mathrm{ml}$. Their mean rate is 1.6 and the standard deviation is 0.5 , whose blood glucose level ranges from $95 \mathrm{mg} / \mathrm{dl}$ to $134 \mathrm{mg} / \mathrm{dl}$ their mean is $113.68 \mathrm{mg} / \mathrm{dl}$ and the standard deviation is 9.56 . For uncontrolled diabetes the salivary flow rate ranges from 0.2 to 1.9 their mean value is 1.36 and the standard deviation is 0.49 , whose blood glucose level ranges from $250 \mathrm{mg} / \mathrm{dl}$ to $430 \mathrm{mg} / \mathrm{dl}$ their mean value is $315 \mathrm{mg} / \mathrm{dl}$ and the standard deviation is 55.91. The salivary flow rate for uncontrolled diabetes is less than prediabetic patients. This may be due to the intake of medication.

Figure 2: Pie chart represents the age distribution of the diabetic patients. 34\% participants were 20-40 years old, $30 \%$ participants were $30-40$ years old, $24 \%$ participants were $40-50$ years old. $12 \%$ participants were $50-60$ years old.

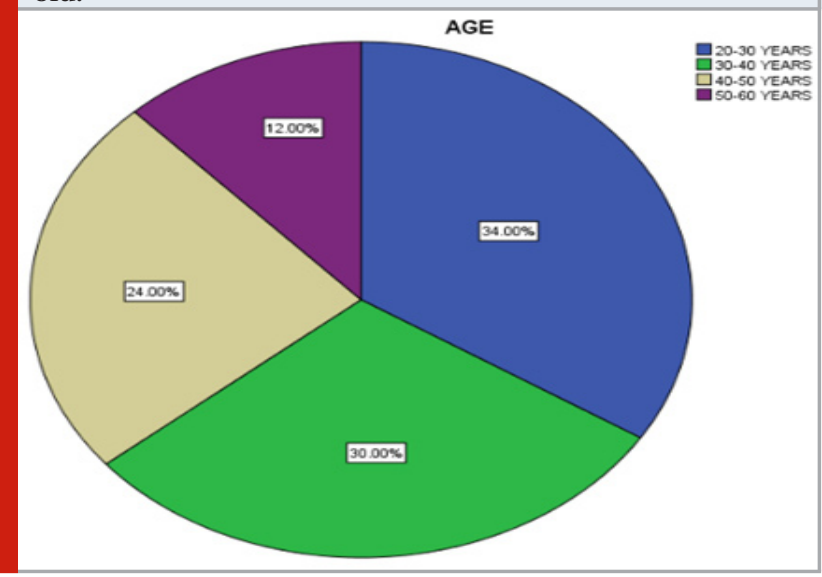

Table 1 . Shows the statistical value for the salivary flow rate of prediabetic and uncontrolled diabetic patients.

\begin{tabular}{|l|r|r|r|r|}
\hline \multicolumn{1}{|c|}{ One-Sample Statistics } \\
\hline & \multicolumn{1}{|c|}{$\mathrm{N}$} & Mean & Std. Deviation & $\begin{array}{c}\text { Std. EIror } \\
\text { Mean }\end{array}$ \\
\hline PREDIABETIC & 25 & 1.60 & .500 & .100 \\
UNCONTROLLEDDIABE & 25 & 1.36 & .490 & .098 \\
TIC & & & & \\
\hline
\end{tabular}

Table 2. Represents the unpaired T-test for salivary flow rate for prediabetic patient and uncontrolled diabetic patients. It was found that Prediabetic patients have greater value than uncontrolled diabetic patients and the difference was also significant statistically. (p-value <0.05).

One.Sample Test

\begin{tabular}{|c|c|c|c|c|c|c|}
\hline & \multicolumn{6}{|c|}{ TestValue $=0$} \\
\hline & \multirow[b]{2}{*}{1} & \multirow[b]{2}{*}{ df } & \multirow[b]{2}{*}{ Sig. $(2.18|1| 100)$} & \multirow{2}{*}{$\begin{array}{l}\text { Nean } \\
\text { Dolference }\end{array}$} & \multicolumn{2}{|c|}{$\begin{array}{l}\text { 958 Confidence Interval of the } \\
\text { Diference }\end{array}$} \\
\hline & & & & & Lowet & Uppert \\
\hline PREDAABETIC & 16000 & 24 & .000 & 1.600 & 1.39 & 1.81 \\
\hline $\begin{array}{l}\text { UNCONTROLLEDDAABE } \\
\text { TIC }\end{array}$ & 13.880 & 24 & .000 & 1.360 & 1.16 & 1.56 \\
\hline
\end{tabular}


Diabetes mellitus is a common chronic metabolic disease with numerous oral and systemic manifestations. The flow of saliva eliminates the carbohydrates which could be metabolized by the bacteria hence the acid produced by the bacteria is removed(Berra et al., 2020). This collaborative oral health study provides comprehensive data for an extremely large cohort of subjects with type 1 diabetes. Because accurate information with respect to medical status, glycemic control, and diagnoses of medical complications was available, analyses of multiple complications and confounding factors as possible(Gerstein and Brian Haynes, 2001). Findings from this cross-sectional oral health assessment are useful for generating hypotheses relating to the causes of xerostomia and hyposalivation, which have been reported for diabetes.

Figure 3: Bar graph shows the association between the salivary flow rate between prediabetic patients and uncontrolled diabetic patients. $\mathrm{X}$ axis denotes the diabetic patients and $\mathrm{Y}$ axis denotes the salivary flow rate. Majority of the uncontrolled diabetic patients have low salivary flow rate than the prediabetic patients. The difference was also significant statistically. [Unpaired t test $\mathrm{P}$ value $0.000(<0.05)]$

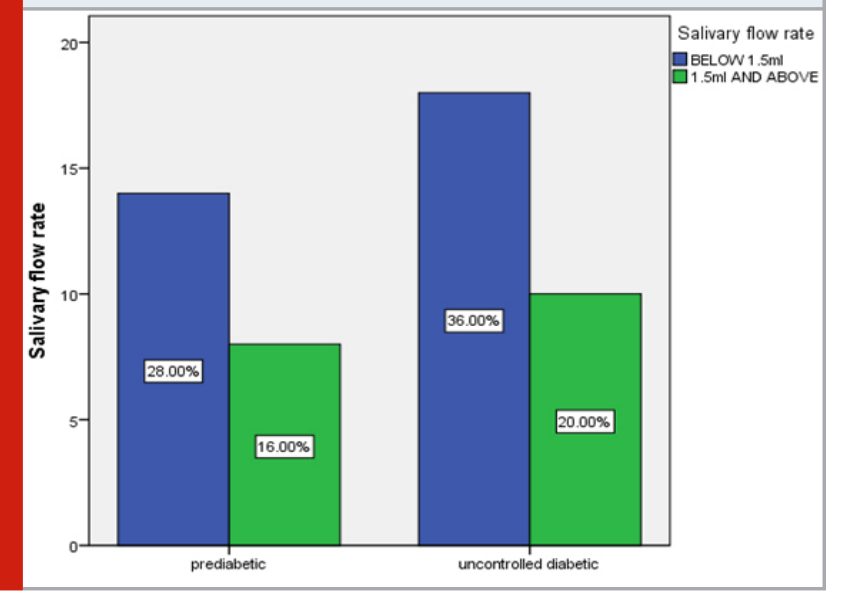

Conclusions made on the basis of this study may not apply to all diabetic populations and may be different if subjects with type 2 diabetes are studied(Rubin, 2009). Oral complications known to be associated with type 1 diabetes include tooth loss, periodontal disease, and a variety of candidal-related soft Significant to our study was that the self-report of salivary impairment and the measured hyposalivation were most related to the diabetic complication of neuropathy. The stimulation of salivary flow is controlled through both sympathetic and parasympathetic innervation(Wright, 2013).

EDC data were available for autonomic and peripheral neuropathy in this type 1 diabetes cohort. These 2 measures were found to be closely related, with 70\% of the subjects with autonomic neuropathy also having a diagnosis of peripheral neuropathy.45 Although both measures of neuropathy were entered into the regression analyses, peripheral neuropathy significantly reduced the flow of the whole saliva observed in the poorly controlled subjects in the present study confirmed the results of previous investigators (Marlow, 2012). Several factors may have caused a decreased flow of saliva in diabetics in poor control. Glucosuria caused by even mild hyperglycemia leads to elevated fluid loss and dehydration which may diminish salivary gland output(Cimperman, 2013).

A systematic review of previously published studies reflects the fact that salivary glucose concentration increases in type $2 \mathrm{DM}$ and a positive correlation exists between blood glucose and salivary glucose; hence, it can be a useful biomarker to monitor type 2 DM.(Challem, 2011). Microvascular alterations in the blood vessels that are commonly seen in type 2 diabetics could also contribute to increased salivary glucose levels(Becker, 2004). Saliva samples collected in the study represented the whole mouth fluid, and therefore, reflect glucose levels due to leakage across the basement membrane of major and minor salivary glands and also from the gingival crevicular fluid. Furthermore, it has been proposed by Belazi that it leads to enhanced leakage of serum components including glucose into the gingival crevicular fluid rather than into saliva due to the basement membrane alterations.

The decrease in the unstimulated whole salivary flow rate in type 2 diabetics is in accordance with previous studies(Samuel 2017). Type 2 DM is known to affect the sympathetic and parasympathetic nervous system of the salivary glands, resulting in decreased salivary secretion, microangiopathy, dehydration, and hormonal changes, which may contribute to the decrease in the salivary flow rate. However, few authors were not ready to establish a significant difference in salivary flow rates between type $2 \mathrm{DM}$ and healthy controls. We found a significant difference in the salivary $\mathrm{pH}$ between the type $2 \mathrm{DM}$ patients and control $(\mathrm{P}<0.01)$, which was similar to other studies. Salivary parameters are altered by metabolic, nutritional, and neurological abnormalities, the hydration status of a person and by drugs like anticholinergics, diuretics, antihistamines, antihypertensives, etc. Limitations of this study is not included the medication history, hydration level and other associated diseases which reduce the salivary flow rate like vitamin A deficiency. Future studies may be done with inclusion of the limitations of our study.

\section{CONCLUSION}

Within the limitations of the study, we conclude that the salivary flow rate for uncontrolled diabetic patients is less than pre-diabetic patients. Salivary flow is required for normal metabolism. It gives protection to the oral cavity. Saliva is an easily available fluid in the human body which plays a major role in our body. The less salivary flow may be due to medication taken by diabetes patients. 


\section{ACKNOWLEDGMENTS}

The authors are thankful to Saveetha Dental college for providing a platform to express our knowledge and the participants of this study for cooperating with us to complete the research.

Conflict of Interest: The author declared that there is no conflict of interest regarding the publication of the article.

\section{REFERENCES}

Asfandiyarova, N. S. (2015) 'A review of mortality in type 2 diabetes mellitus', Diabetes mellitus, pp. 12-21. doi: $10.14341 / \mathrm{dm} 6846$.

Babiker, A. et al. (2020) 'Uncontrolled diabetes: A difficult mother or a mother in difficulty?', Journal of family medicine and primary care, 9(3), pp. 17721774.

Becker, G. (2004) Prediabetes: What You Need to Know to Keep Diabetes Away. Da Capo Press.

Berra, C. C. et al. (2020) 'Clinical efficacy and predictors of response to dulaglutide in type-2 diabetes', Pharmacological research: the official journal of the Italian Pharmacological Society, 159, p. 104996.

Bikbov, M. M. and Surkova, V. K. (2016) 'Cornea and its changes in diabetes mellitus: the review', Diabetes mellitus, pp. 479-485. doi: 10.14341/dm7972.

Challem, J. (2011) AARP Stop Prediabetes Now: The Ultimate Plan to Lose Weight and Prevent Diabetes. John Wiley \& Sons.

Cimperman, S. (2013) The Prediabetes Detox: A WholeBody Program to Balance the Blood Sugar, Increase Energy, and Reduce Sugar Cravings. New Harbinger Publications.

Dawes, C. and Watanabe, S. (1987) 'The Effect of Taste Adaptation on Salivary Flow Rate and Salivary Sugar Clearance', Journal of Dental Research, pp. 740-744. doi: 10.1177/00220345870660030701.

Erismis, B. (2016) 'Management of Hypertriglyceridemia in Uncontrolled Type 2 Diabetes Mellitus Patients: 2 Case Studies', Journal of Diabetes, Metabolic Disorders \& Control. doi: 10.15406/jdmdc.2016.03.00072.

Galloway, J. A., Potvin, J. H. and Shuman, C. R. (1988) Diabetes Mellitus.

Garrett, J. R., Ekström, J. and Anderson, L. C. (1998) Glandular Mechanisms of Salivary Secretion. Karger Medical and Scientific Publishers.

Gerstein, H. C. and Brian Haynes, R. (2001) Evidencebased Diabetes Care. PMPH-USA.

Habibe, C.-H. et al. (2020) 'Comparison of salivary cytokines levels among individuals with Down syndrome, cerebral palsy and normoactive', Journal of clinical and experimental dentistry, 12(5), pp. e446-e451.

Hegde, S. (2016) 'A comparative evaluation of salivary flow rate, $\mathrm{pH}$, buffering capacity, calcium and total protein levels in pregnant and non pregnant women', Journal of Advanced Medical and Dental Sciences Research, pp. 92-95. doi: 10.21276/jamdsr.2016.4.4.20.

Jongerius, P. H., van Limbeek, J. and Rotteveel, J. J. (2004) 'Assessment of Salivary Flow Rate: Biologic Variation and Measure Error', The Laryngoscope, pp. 1801-1804. doi: 10.1097/00005537-20041000000023.

Keen, H. (2008) 'Epidemiologic Aspects of Type 2 Diabetes Mellitus in Europe', The Epidemiology of Diabetes Mellitus, pp. 111-120. doi: 10.1002/9780470779750. ch9.

Lee, K.-H., Jung, E.-S. and Choi, Y.-Y. (2020) 'Effects of lingual exercises on oral muscle strength and salivary flow rate in elderly adults: a randomized clinical trial', Geriatrics \& gerontology international. doi: 10.1111/ ggi.13944.

LeRoith, D., Taylor, S. I. and Olefsky, J. M. (2004) Diabetes Mellitus: A Fundamental and Clinical Text. Lippincott Williams \& Wilkins.

Marlow, S. (2012) The Rise in Prediabetes and the Threat of Insulin Resistance and HyerGlycemia. SandSPublishing.

Metz, R., Nice, M. and LaPlaca, G. (1967) 'Evaluation of an Eight-hour Therapeutic Regimen in Uncontrolled Diabetes', Diabetes, pp. 341-345. doi: 10.2337/ diab.16.5.341.

Molitvoslovova, N. A. and Galstyan, G. R. (2013) 'Osteoporosis and diabetes mellitus: a modern viewpoint', Diabetes mellitus, pp. 57-62. doi: 10.14341/2072-03513598.

Norasettkul, K., Gonlachanvit, S. and Patcharatrakul, T. (2017) '24-h Esophageal PH/Impedance Monitoring Profiles in Patients with Normal Salivary Flow Rate and Low Salivary Flow Rate (Xerostomia) in Patients who were Suspected of Gerd', Gastroenterology, p. S329. doi: 10.1016/s0016-5085(17)31372-0.

Rubin, A. L. (2009) Prediabetes For Dummies. John Wiley \&t Sons.

Samuel, P. (2017) Prediabetes Diet Plan - Prediabetes Detox and Prediabetes Diet to Prevent Diabetes. Createspace Independent Publishing Platform.

Shalal, P. (no date) 'Effects of Black Tea on Salivary pH and Flow Rate'. doi: 10.20944/preprints201706.0109. v1.

Syrjälä, A.-M. et al. (2011) 'Salivary flow rate and periodontal infection - a study among subjects aged 75 years or older', Oral Diseases, pp. 387-392. doi: 10.1111/j.1601-0825.2010.01764.x.

Wright, H. (2013) The Prediabetes Diet Plan: How to Reverse Prediabetes and Prevent Diabetes through Healthy Eating and Exercise. Ten Speed Press.

Zarif, N. and Norris, A. (2014) 'Choreoathetosis: a result of uncontrolled diabetes', Practical Diabetes, pp. 306-306a. doi: 10.1002/pdi.1888.

Zerbe, R. L., Vinicor, F. and Robertson, G. L. (1979) 'Plasma vasopressin in uncontrolled diabetes mellitus', Diabetes, pp. 503-508. doi: 10.2337/diabetes.28.5.503. 